\title{
Identification of the Sex Pheromone of the Mulberry Pyralid, Glyphodes pyloalis WALKER (Lepidoptera: Pyralidae)
}

\author{
Hiroshi Honda, Tetsu Ando, ${ }^{1}$ Yasushi Ogura, ${ }^{1}$ \\ Tutomu TERAMINE ${ }^{2}$ and Rinya UEDA ${ }^{2}$ \\ Laboratory of Applied Entomology, Facully of Agriculture, \\ The University of Tokyo, Tokyo 113, Japan \\ 1 Department of Plant Protection, Faculty of Agriculture, \\ Tokyo University of Agriculture and Technology, \\ Fuchu, Tokyo 183, Japan \\ 2 Kochi Sericultural Experiment Station, Kuzume, \\ Tosayamada, Kochi 782, Japan
}

(Received September 12, 1989; Accepted November 27, 1989)

\begin{abstract}
The major component of the female sex pheromone of $G$. pyloalis is $(E, E, Z)-10,12,14-$ hexadecatrienyl acetate, as evidenced by analyses of ovipositor extracts by GLC and HPLC, and comparison of EAG responses of the male moths to synthetic compounds. The amount of pheromone produced was 1-2 ng/female. No peak for any other isomers of the compound was observed on GLC analysis. Field tests of all possible geometric isomers of synthetic $10,12,14$-hexadecatrienyl acetate showed that only $(E, E, Z)$-configuration had activity. Traps baited with a silicone rubber septum impregnated with $0.3 \mathrm{mg}$ of the $(E, E, Z)$-isomer, which was protected with an antioxidant, caught more G. Pyloalis males than traps baited with virgin female moths.
\end{abstract}

\section{INTRODUCTION}

The mulberry pyralid, Glyphodes pyloalis WALKER, is a serious pest of mulberry, Morus alba in East Asian countries. The presence of a sex pheromone, which could be extracted from the female abdominal tips, was demonstrated by SEOL et al. (1986b). 10,12,14-hexadecatrienyl acetate (HDTA) was identified as a female sex pheromone of this moth, but the stereochemistry of the pheromone remained as a next step of research (SEOL et al., 1987).

The HDTA of 8 geometric isomers were synthesized by 6 routes (ANDo et al., 1983). The final identification of the natural pheromone needs to be confirmed by co-chromatographic analyses and by field-assay of each isomer.

This paper deals with assignment of the configuration of the natural pheromone of the mulberry pyralid by GLC, HPLC and EAG analyses and a field assay.

\section{MATERIALS AND METHODS}

Insect. Mulberry pyralid larvae were reared on mulberry leaves or an artificial diet (SEol et al., 1986a) at $24 \pm 1^{\circ} \mathrm{C}, 60-70 \%$ R.H., and $15 \mathrm{~L}-9 \mathrm{D}$. The pupae were 
sexed and kept in separate cages to prevent from mating after emergence. The moths were also provided with $6-8 \%$ sugar solution from a cotton pad placed on the top screen of the cage.

Pheromone extract and chemicals. After 3-day old virgin female moths were carefully anesthetized with $\mathrm{CO}_{2}$, their abdominal tips were cut off with fine scissors. The abdominal tips were extracted with $n$-hexane $(50 \mu \mathrm{l} /$ tip) containing ethoxyquine (6ethoxy-2,2,4-trimethyl-1,2-dihydroquinoline: $0.1 \mathrm{mg} / \mathrm{ml}$ ) as antioxidant (BICKoff et al., 1954) for $\mathrm{I} \mathrm{h}$ at room temperature, and then filtrated through a cotton pad in a Pasteur pipette. The pooled extracts were stored at $-20^{\circ} \mathrm{C}$ until use, and analyzed by GLC and HPLC without further purification.

All geometric isomers of 10,12,14-HDTA and serial hexadecenyl acetates (HDAs) were synthesized by the second author's group (AnDo et al., 1988). GC analyses showed each of these compounds to be $>99 \%$ pure.

GLC and HPLC analyses. GLC analyses were performed on a GC-4B (Shimadzu) fitted with a FID and a fused silica capillary column of PEG $20 \mathrm{~m}(0.25 \mathrm{~mm}$ i.d. $\times 25 \mathrm{~m}$ length), flow rate $\left(\mathrm{N}_{2}\right) 0.6 \mathrm{~kg} / \mathrm{cm}^{2}$ at $70-230^{\circ} \mathrm{C}\left(5^{\circ} \mathrm{C} / \mathrm{min}\right)$. HPLC analyses were performed with a LC-6A system (Shimadzu) equipped with UV detector (SPD-6A) operated at $265 \mathrm{~nm}$ and a Senshyu Pak ODS-3151-SH column (Senshyu Kagaku Co., 8 $\mathrm{mm}$ i.d. $\times 15 \mathrm{~cm}$ length). Acetonitrile-water $(90: 10)$ was used for the mobile phase at a flow rate of $2.0 \mathrm{ml} / \mathrm{min}$.

Electroantennogram assay. Electroantennogram (EAG) techniques used were similar to those previously described (Schneider, 1957; Honda et al., 1986). The head of a moth was placed on its occiput on an insect saline-soaked tissue paper covering a small styrofoam disc in a Petri dish, with the rostraventral side of its antenna facing a stimulus source. The antennal top was cut off, and was inserted into a glass capillary recording electrode filled with saline. The electrode led to a microelectrode amplifier DPA100E (Daiya Medical System, Tokyo) via an $\mathrm{Ag}-\mathrm{AgCl}$ wire. Another $\mathrm{Ag}-\mathrm{AgCl}$ wire was set on the saline-soaked tissue paper as an indifferent electrode. The generated potential was amplified and observed on a pen recorder. Test chemicals were delivered through a $5 \mathrm{~cm}$ glass hypodermic syringe. A glass cartridge $(1.2 \mathrm{~cm} \mathrm{ht})$ was internally lined with a strip of filter paper to which the test compound $(10 \mu \mathrm{g})$ was added. From a distance of ca. $1 \mathrm{~cm}$, a $1 \mathrm{ml}$ puff of odor-laden air was delivered to the antenna.

Field assay. Field assays were conducted in 2 fashions in the mulberry fields of the Kochi Sericultural Experiment Station to compare attractancy of various synthetic HDTAs to virgin females. The first set of experiments was made between May and July, 1989. Traps were baited with 0.1 to $0.3 \mathrm{mg}$ HDTA/silicone rubber septum. The second set of experiments was done between August and October of the same year. Each isomer of HDTA was protected from oxidative decomposition with ethoxyquine $(10 \mu \mathrm{g}$ to $3 \mathrm{mg} / \mathrm{septum})$. Each treatment was set on a sticky trap $(40 \times 25 \times$ $5.5 \mathrm{~cm}$, Takeda Chemical Ind., Ltd.) or a hand-made water-pan trap $(45 \times 30 \times 8$ $\mathrm{cm})$. These traps were hung randomly, $1.5 \mathrm{~m}$ above the ground on wooden stands placed at $10 \mathrm{~m}$ intervals. Virgin female and unbaited control traps were also included. Three virgin females, caged in a small mesh ball, were replaced every 3 days. In order to determine the efficacy of HDTA-loaded septa through time, renewals were not made unless otherwise stated. 


\section{RESULTS}

\section{EAG responses to serial isomers}

EAG responses of the male moths to serial hexadecenyl acetates (HDAs) were measured in order to elucidate the double bond position and the configuration form (Fig. 1-a). Large responses were caused by $(E)-10-,(E)-12-,(E)-13-,(E)-14$, and $(Z)$-14-HDAs. $(Z)-14$ HDA showed the largest EAG activity of the $(Z)$-isomers. These EAG profiles clearly supported our previous conclusion that a main component of the natural pheromone is 10,12,14-HDTA (SEOL et al., 1987).

Configuration of conjugated double-bond system was defined by EAG technique with Loberia botrana. In this case, $(E)$-7- and $(Z)$-9-isomers were the most active in EAG profiles of serial monounsaturated 12 carbon acetates, and $(E, Z)$-7,9-dodecadienyl acetate was proven to be a natural pheromone (Roelofs et al., 1973; Buser et al., 1974). Therefore, our result strongly suggests that stereochemistry of the natural pheromone might be $(E, E, Z)$ or $(E, E, E)$.

EAG analyses of the 8 isomers of $10,12,14$-HDTA demonstrated that the highest EAG activity resided with the $(E, E, Z)$-isomer (Fig. 1-b), and suggestes that this might be the configuration of the natural pheromone.

\section{Co-chromatography with synthetic standards}

Prior to co-chromatographic analyses of the natural pheromone with synthetic standards, retention times $(R t)$ of all isomers of 10,12,14-HTDA were determined by GLC and HPLC. As shown in Table $1,(E, E, Z)-,(Z, Z, Z)$ - and $(E, Z, Z)$-isomers had the largest $R t$ values on GLC. There was little difference between the first two of these isomers; distinctions could not be made even by HPLC.

When an aliquot of the crude pheromone extract was analyzed by HPLC, only one peak (Rt $18.33 \mathrm{~min})$ was detected, coincident with the $(E, E, Z)$ - or $(Z, Z, Z)$-isomers

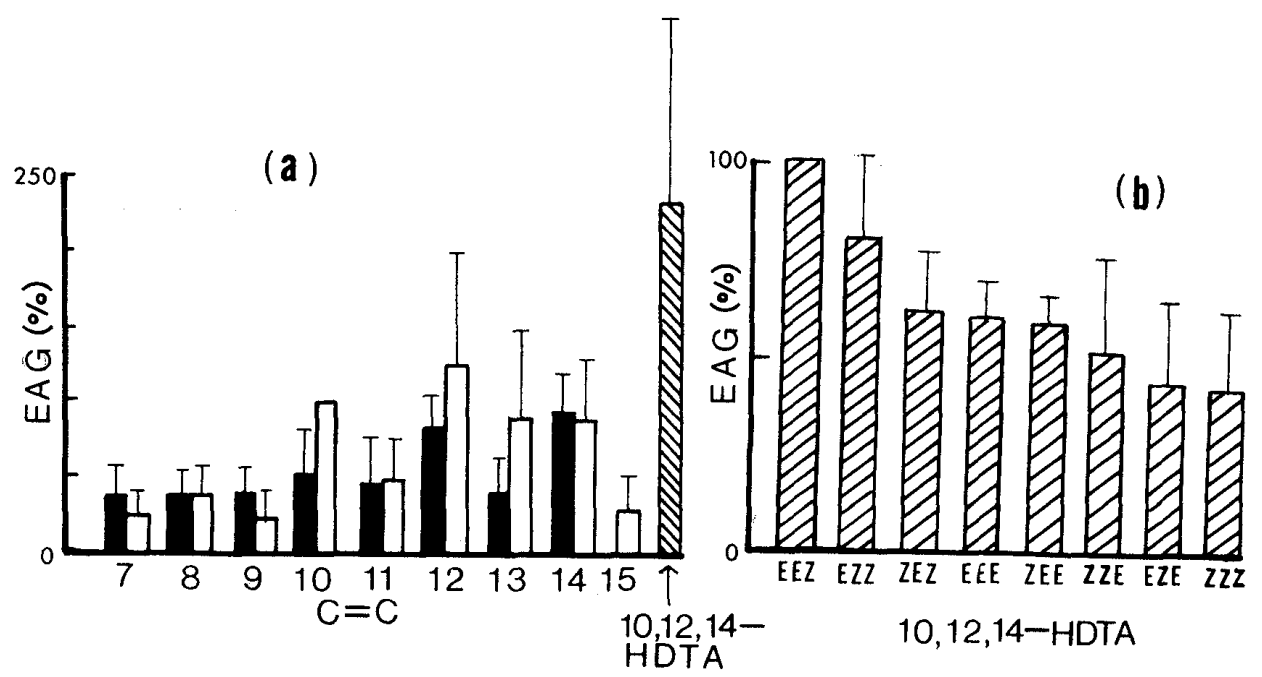

Fig. 1. EAG responses of $G$. pyloalis males to hexadecenyl acetates (a) ( $\square: Z$ isomers, $\square: E$ isomers, $\$$ : synthetic $(E, E, Z)-10,12,14$-HDTA, numbers indicate position of the double bond) and 8 isomers of 10,12,14-HDTA (b). Responses to all test chemicals were expressed relative to $(E)$-10-isomer (a) and $(E, E, Z)$-10,12,14-isomer (b). 
Table 1. GLC and HPLC Rt values ( $\mathrm{min}$ ) of the 8 geometric isomers. of 10,12,14-hexadecatrienyl acetate

\begin{tabular}{lllllllll}
\multirow{2}{*}{ Analysis } & \multicolumn{10}{c}{ Isomer } \\
\cline { 2 - 8 } & ZEE & ZZE & ZEZ & EZE & EEE & EEZ & ZZZ & EZZ \\
\hline GLC (PEG-20 M) & 29.33 & 29.33 & 29.44 & 29.79 & 29.85 & 30.17 & 30.17 & 31.38 \\
HPLC (ODS) & 16.9 & 17.1 & 16.0 & 16.2 & 21.8 & 18.3 & 18.4 & 16.9 \\
\hline
\end{tabular}

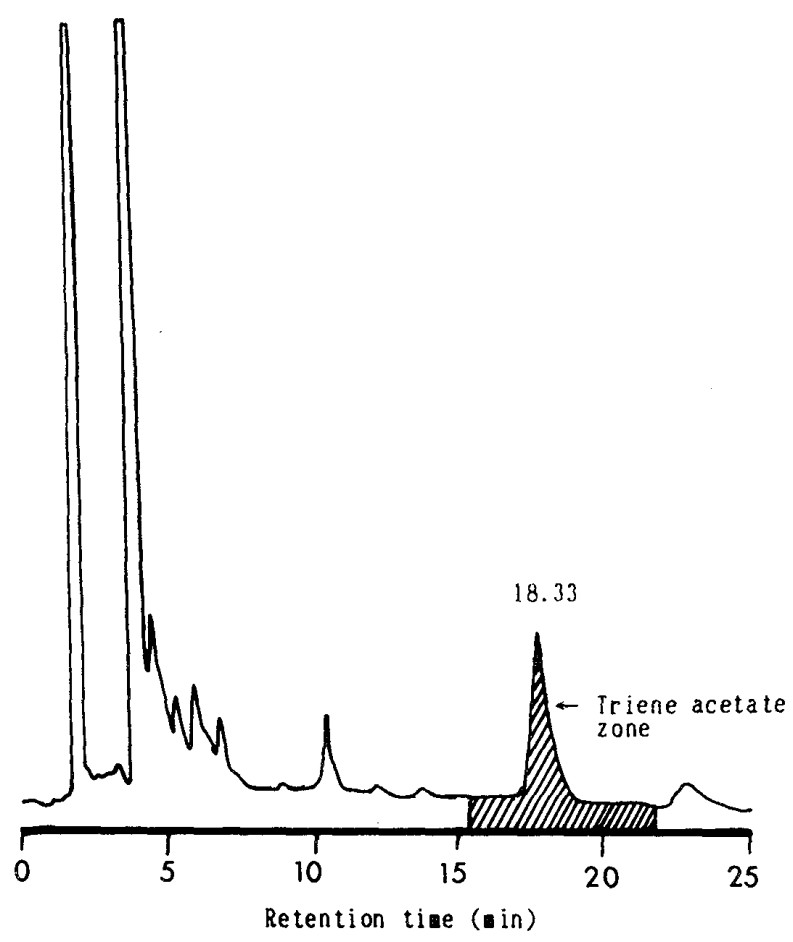

Fig. 2. HPLC chromatogram of a crude sex pheromone extract of $G$. pyloalis females on ODS column.

(Fig. 2). This fraction was further analyzed by GLC, and then a single peak (Peak A) appeared at $R t 30.17 \mathrm{~min}$, again assignable as $(E, E, Z)$ - or $(Z, Z, Z)$-isomers (Fig. 3, Table 1). Confirmation of the identity of Peak $A$ was achieved by co-chromatography with each synthetic isomer which amplified the small retention time difference. When each isomer was co-chromatographed with the crude pheromone extract, only the $(E, E, Z)$ - and $(Z, Z, Z)$-isomers completely overlapped with the Peak A (Fig. 3). Yield of the pheromone from the virgin females was relatively low, ca. 1-2 ng/female in GLC analyses.

\section{Field assay}

The results of the GLC analyses indicated that the most likely isomers constituting the mulberry pyrarid pheromone were $(E, E, Z)$ - or $(Z, Z, Z)-10,12,14-H D T A s$. However, on considering the EAG result, the $(Z, Z, Z)$-isomer was ruled out since it had little biological activity. In the initial field assay, all 8 isomers were individually tested, without added antioxiant. The $(E, E, Z)$-isomer was the most effective, retaining 


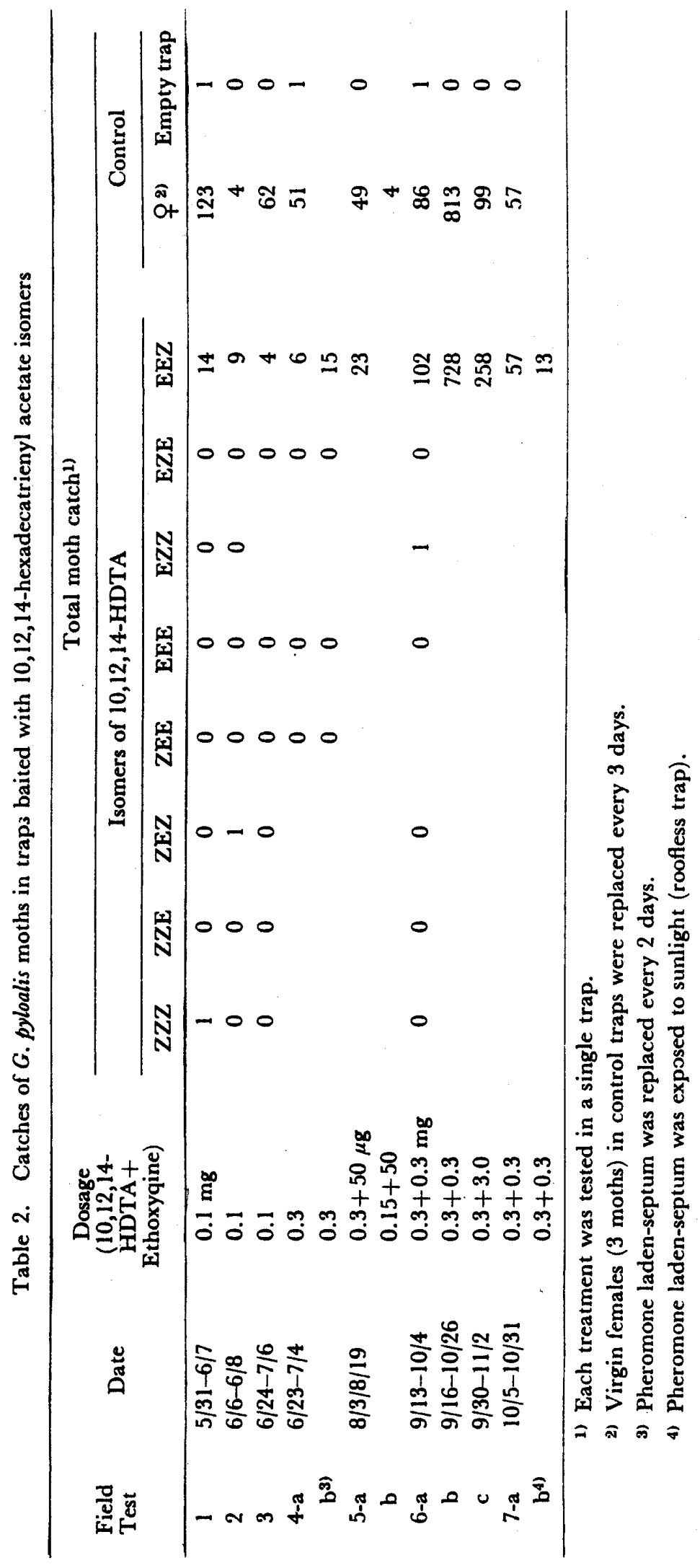



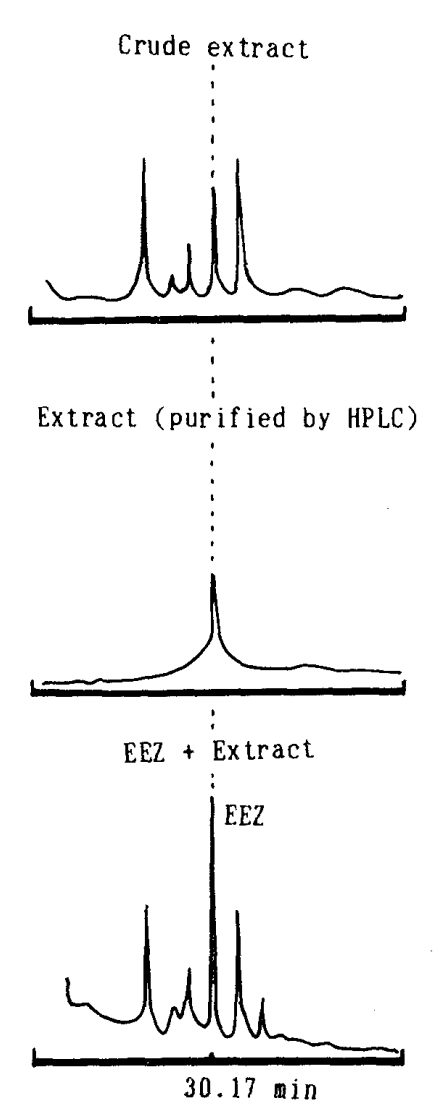
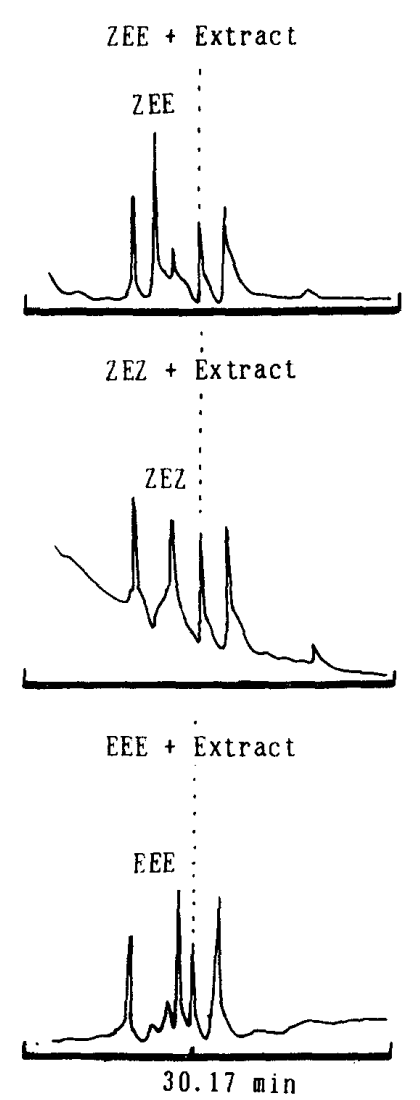

Fig. 3. Co-chromatograms of a serial geometric isomers of 10,12,14-hexadecatrienyl acetate and the pheromone extract on PEG $20 \mathrm{~m}$ column.

its efficacy for 2 or 3 days. However total catches were lower than for the virgin female bait traps (Table 2, Field Test 1,2 and 3). These lower catches may be attributed to decomposition of the isomer, because conjugated triene compounds are, in general, unstable without protection by antioxidants. The total catches of the isomer in Field Test 4-b, where the loaded septum was replaced every 2 days, was 2.5 times higher than that of Field Test 4-a, in which the septum was not reloaded (Table 2).

The catches of the mulberry pyralid by the $(E, E, Z)$-isomer increased when the isomer was protected from oxidative decomposition by ethoxyquine (Table 2, Field Test 5-a and -b and 6-a, -b and -c). As seen in Field Test 6-a, the other 7 geometric isomers of 10,12,14-HDTA showed no attractancy to the male moths even when they were mixed with antioxidant.

Pheromones protected by an antioxidant and exposed to longer periods of sunlight undergo more extensive photo-isomerization which reduces their activity (IDEses and ShanI, 1988). A similar result was also obtained in Field Test 7 , where attractancy of the trap with no roof (Field Test 7-b) was significantly less than that in Field Test 7-a.

\section{DISCUSSION}

On the basis of EAG profiles, GLC and HPLC analyses and field tests, we concluded that the main component of the sex pheromone of the mulberry pyralid is $(E, E, Z)-10,12$, 
14-HDTA. This is the first record of Pyralidae pheromone with 3 double bonds. Two other types of triunsaturated pheromone $(E, Z, Z)-4,7,10$-tridecatrienyl acetate (YAMAoKA et al., 1976; Persoons et al., 1976) and 4,6,10-hexadecatriene derivatives (BeEvor et al., 1986), have been identified from Gelechiidae species. In addition, $(Z, Z, Z)-9,12$, 15-octadecatrienal (Hill and Roeloes, 1982; Hill et al., 1982) and ( $Z, Z, Z)-3,6,9$ heneicosatriene (ConNer et al., 1980) have been found in the Arctiidae, and the latter compounds and $(Z, Z, Z)-3,6,9$-eicosatriene have been also identified as the sex pheromone components of Noctuidae species, Anticarsia gemmatalis (HeAth et al., 1983), Caenurgina erechta (UNDerhill et al., 1983) and Mocis disseverans (LANDolt et al., 1986). These 5 types of triene compounds vary from zero or two conjugated double bonds, and the double bonds are located near the center of the skeleton. However, our triene acetate has 3 uniquely conjugated double bonds remote from the other functional group.

With several species, e.g. Lobesia botrana (Roelofs et al., 1973) and Dendrolims spectabilis (ANDo et al., 1982), a conjugated diene system has been defined by the EAG standard technique. In cases inwolving multiple double bonds, BEEvor et al. (1986) also predicted $(E, Z, Z)-4,6,9-\mathrm{HDT}$ A and/or the $(E, E, Z)$-isomer as the sex pheromone component(s) of Conopomorpha cramerella in the same way. As shown in Fig. 1-a, EAG response profiles of the mulberry pyralid to serial HDAs provided the final identification of the active component. These facts indicate that even when 3 double bonds are all conjugated, monounsaturated standards can be used to predict the position and configuration of all the double bonds in sex pheromone molecules.

Because of its low EAG activity and lack of attractancy in the field assay, $(Z, Z, Z)$ isomer was excluded as a mulberry pyralid pheromone candidate. Since this isomer was unseparable from the $(E, E, Z)$-isomer by GLC and HPLC (as shown in Table 1), we have no direct evidence of its presence or absence in the crude extract.

The major problems with the use of the pheromone in a field situation are its relatively high rate of evaporation and its photo and oxidative labilities. These may be overcome by the development of a better method of dispersal. At the present time, however, effective field life of the synthetic pheromone was ca. 20 days. This is probably insufficient for practical use in mulberry plantations.

\section{ACKNOWLEDGEMENTS}

We thank Dr. R. TorA of the University of California, Berkeley for his kind reading of the manuscript. We are also grateful to Prof. Y. Matsumoto of the Tohoku University and Prof. T. Ikeshoji of the University of Tokyo for their encouragement during our work.

\section{REFERENCES}

Ando, T., Y. Ogura, M. Koyama, M. Kurane, M. Ughiyama and K. Y. Seol (1988) Syntheses and NMR analyses of eight geometrical isomers of 10,12,14-hexadecatrienyl acetate, sex pheromone candidates of the mulberry pyralid. Agric. Biol. Chem. 52: 2459-2468.

Ando, T., M. H. Vu, S. Yoshida, N. Takahashi, S. Tatsuki, K. Katagiri, A. Yamane, T. Ikeda and S. Yamazaki (1982) (5E, 7E)-5,7-Dodecandien-1-ol: female sex pheromone of the pine moth Dendrolimus spectabilis Butt.er. Agric. Biol. Chem. 46: 709-715.

Beevor, P. S., A. Cork, D. R. Hall, B. F. Nesbitt, R. K. Day and J. D. Mumford (1986) Components of female sex pheromone of cocoa pod borer moth, Conopomorpha cramerella. J. Chem. Ecol. 12: 1-22. 
Bickoff, F. M., A. L. Livingston, J. Guggolz and C. R. Thompson (1954) Quinoline derivatives as antioxdants for carotene. J. Agric. Food Chem. 2: 1229-1230.

Buser, H. R., S. Rauscher and H. Arn (1974) Sex pheromone of the Lobesiak botrana: (E,Z)-7,9-dodecadienyl acetate in the female grape vine moth. Z. Naturforsch. 29: 781-783.

Conner, W. E., T. Eisner, R.K. Van Der Meer, A. Guerrero, D. Chringelli and J. Meinwald (1980) Sex attractant of an arctiid moth (Utethesia ornatrix): a pulsed chemical signal. Behav, Ecol. Sociobiol. 7: 55-63.

Heath, P. R., J. H. Tumulinson, N. C. Leppla, J. R. Malaughlin, B. Dueben, E. Dundulis and R. H. Guy (1983) Identification of the sex pheromone produced by female velvetbean caterpillar moth. J. Chem. Ecol. 9: 645-656.

Hill, A. S., B. G. Kovalev, N. L. Nikolaeva and W. L. Roelofs (1982) Sex pheromone of the fall webworm moth, Hyphantria cunea. J. Chem. Ecol. 8: 383-396.

Hill, A. S. and W. L. Roelofs (1982) Sex pheromone of the saltmarsh caterpillar moth, Estigmene acrea. J. Chem. Ecol. 7: 655-668.

Honda, H., Y. Maruyama and Y. Matsumoto (1986) Comparisons in EAG response to $n$-alkyl compounds between the fruit- and Pinaceae-feeding type of yellow peach moth, Conogethes punctiferalis (Guenée) (Leidoptera: Pyralidae). Appl. Ent. Zool. 21: 126-133.

Ideses, R. and A. Shani (1988) Chemical protection of pheromones containing an internal conjugated diene system from isomerization and oxidation. J. Chem. Ecol. 14: 1657-1669.

Landolt, P. J., R. R. Heath and N. C. Leppla (1986) ( $Z, Z, Z)-3,6,9-$ Eicosatriene and $(Z, Z, Z)-3,6,9-$ heneicosatriene as sex pheromone components of grass looper, Morcis disseverns (Lepidoptera: Noctuidae). Environ. Entomol. 15: 1272-1274.

Persoons, C. J., S. Voerman, P. E. J. Verwiel, F. J. Ritter, W. J. Nooijen and A. K. Minks (1976) Sex pheromone of the potato tuberworm moth, Phthorimaea operculella: isolation, identification and field evaluation. Entomol. Exp. Appl. 20:289-300.

Roelofs, W. L., J. Kochansky, R. T. Cardé and A. H. Rauscher (1973) Sex attractant of the grape vine moth, Lobesia botrana. Bull. Soc. Entomol. Sci. 46: 71-73.

Sahneider, D. (1957) Elektrophysiologische Untersuchungen von Chemo- und Mechanorezeptoren der Antenne des Seidenspinners Bombyx mori. Z. vergl. Physiol. 40: 8-41.

Seol, K. Y., H. Honda and Y. Matsumoto (1986a) Artificial diets for mass-rearing of the lesser mulberry pyralid, Glyphodes pyloalis WALKer (Lepidoptera: Pyralidae). Appl. Ent. Zool. 21: 109-113.

SEol, K. Y., H. Honda and Y. Matsumoto (1986b) Mating behavior and the sex pheromone of the lesser mulberry pyralid, Glyphodes pyloalis WALker (Lepidoptera: Pyralidae). Appl. Ent. Zool. 21 : 228-235.

Seol, K. Y., H. Honda, K. Usur, T. Ando and Y. Matsumoto (1987) 10,12,14-Hexadecatrienyl acetate: Sex pheromone of the mulberry pyralid, Glyphodes pyloalis WAlker (Lepidoptera: Pyralidae). Agric. Biol. Chem. 51 : 2285-2287.

Underhill, E. W., P. Palaniswamy, S. R. Abrams, B. K. Bailey, W. F. Steck and M. D. Chisholn (1983) Triunsaturated hydrocarbons, sex pheromone components of Caenurgina erechta. J. Chem. Ecol. 9: 1413-1423.

Yamaoka, R., H. Fukami and S. Ishi (1976) Isolation and identification of the female sex pheromone of the potato tuberworm moth, Phthorimaea operculella (ZELler). Agric. Biol. Chem. 40: 1971-1977. 